\title{
Risk factors for lung disease progression in children with cystic fibrosis
}

\author{
To the Editor:
}

We read with interest the recent paper by VAN HorcK et al. [1], which studied 545 children followed for 5 years with longitudinal data from the Dutch Cystic Fibrosis registry. Data from 2009 to 2014 showed that proton pump inhibitor (PPI) use was associated with annual decline of \% predicted forced expiratory volume in $1 \mathrm{~s}$ and future pulmonary exacerbation rates. In a discussion of potential mechanisms, the authors considered that bacteria are normally killed by acid conditions in the stomach but that gastric $\mathrm{pH}$ is raised following PPI use. It was therefore hypothesised that with extra-oesophageal reflux, surviving pathogens could reach the upper airway and be aspirated.

We have described the microbiomes isolated from the gastric juice and sputum of PPI-treated adults with cystic fibrosis (CF) lung disease [2]. This showed that all gastric and sputum cultures grew bacteria and/or fungi. Possible communication between the gut and lung microbiome in CF were indicated by describing identical strains of Pseudomonas aeruginosa in sputum and gastric juice from the same patient.

The swallowing of expectorated sputum is a normal homeostatic mechanism that could explain our observation of identical microorganisms in the gut and lung environments. We also documented symptoms of extra-oesophageal, gastroduodenal reflux, a known precursor to aspiration. This indicates the possibility of gut to lung movement of micro-organisms, considered by VAN HORCK et al. [1], and a potential mechanism long-recognised in lung disease. Micro-aspiration and potential gut to lung microbial movement has also been shown in radiolabel studies of normal subjects $[3,4]$.

In supporting data we have looked at the relationship between $\mathrm{pH}$ and the microbiology of gastric juice. We found that microbes, including $P$. aeruginosa, were detected in gastric juice where $\mathrm{pH}$ was $\geqslant 4.0$ [5]. This supports the concept that PPI use could encourage the survival of micro-organisms in gastric juice, which could be translocated to the lung following reflux and micro-aspiration.

A recent global survey of patients, carers and clinicians has indicated that "relieving gastrointestinal symptoms" and "simplifying treatment" were in the top three of 10 consensus research priorities identified in CF [6]. We therefore agree with the view expressed by van HorcK et al. [1], that the association between PPI use and lung disease progression in CF requires investigation. We feel that such "aerodigestive" studies may be relevant for other chronic lung diseases where reflux has been implicated [7] and where PPI treatment is common. For example, non-CF patients with co-existing bronchiectasis and reflux have increased chronic infection, and reduced pulmonary function and quality of life [8], with associated increase in mortality [9].

Hafez Al Momani ${ }^{1}$, Audrey Perry ${ }^{2}$, Rhys Jones ${ }^{3}$, Melissa McDonnell ${ }^{4}$, Amaran Krishnan ${ }^{3}$, Andrew Robertson ${ }^{5}$, Mike Griffin $^{3}$, Robert Rutherford ${ }^{4}$, Malcolm Brodlie $\odot^{6}$, Jeff Pearson ${ }^{7}$, Steve Bourke ${ }^{8}$ and Chris Ward $\oplus^{9}$

${ }^{1}$ Medical Microbiology, The Hashemite University, Zarqa, Jordan. ${ }^{2}$ Dept of Medical Microbiology, The Freeman Hospital, Newcastle upon Tyne Hospitals Trust, Newcastle Upon Tyne, UK. ${ }^{3}$ Northern Oesophago-Gastric Unit, Royal Victoria Infirmary, Newcastle Upon Tyne, UK. ${ }^{4}$ Respiratory Medicine, Galway University Hospitals, Galway, Ireland. ${ }^{5}$ Royal Infirmary of Edinburgh, Edinburgh, UK. ${ }^{6}$ Great North Children's Hospital, Paediatric Respiratory Medicine, Institute of Cellular Medicine, Newcastle University, Newcastle Upon Tyne, UK. ${ }^{7}$ Institute for Cell and Molecular Bioscience, Newcastle University, Newcastle Upon Tyne, UK. ${ }^{8}$ Newcastle Adult Cystic Fibrosis Centre, Royal Victoria Infirmary, Newcastle upon Tyne, UK. ${ }^{9}$ Institute for Cellular Medicine, Newcastle University, Newcastle Upon Tyne, UK.

Correspondence: Chris Ward, Institute of Cellular Medicine, Newcastle University, Medical School, Framlington Place, Newcastle upon Tyne, NE2 4HH, UK. E-mail: chris.ward@ncl.ac.uk

@ERSpublications

We call for studies of widespread use of proton pump inhibitor therapy in people with cystic fibrosis and chronic lung disease; these should evaluate patient benefit and potential iatrogenic effects, including dysregulation of aerodigestive homeostasis http://ow.ly/ym6H30lxxZu

Cite this article as: $\mathrm{Al}$ Momani $\mathrm{H}$, Perry A, Jones $\mathrm{R}$, et al. Risk factors for lung disease progression in children with cystic fibrosis. Eur Respir J 2018; 52: 1801492 [https://doi.org/10.1183/13993003.01492-2018]. 
Received: Aug 072018 | Accepted: Aug 142018

Conflict of interest: H. Al Momani has nothing to disclose. A. Perry has nothing to disclose. R. Jones has nothing to disclose. M. McDonnell has nothing to disclose. A. Krishnan has nothing to disclose. A. Robertson has nothing to disclose. M. Griffin has nothing to disclose. R. Rutherford has nothing to disclose. M. Brodlie reports grants from Pfizer and Roche Diagnostics, honoraria for talking at educational meetings (paid to Newcastle University) from Novartis, honoraria and travel expenses for talking at educational meetings (paid to Newcastle University) from TEVA and Roche Diagnostics, and travel expenses to attend educational meetings from Boehringer Ingelheim, outside the submitted work. J. Pearson has nothing to disclose. S. Bourke has nothing to disclose. C. Ward has nothing to disclose.

Support statement: This work was funded by Medical Research Foundation (MRF-091-0001-RG-GARNE). Funding information for this article has been deposited with the Crossref Funder Registry.

\section{References}

1 van Horck M, van de Kant K, Winkens B, et al. Risk factors for lung disease progression in children with cystic fibrosis. Eur Respir J 2018; 51: 1702509.

2 Al-Momani H, Perry A, Stewart CJ, et al. Microbiological profiles of sputum and gastric juice aspirates in cystic fibrosis patients. Sci Rep 2016; 6: 26985.

3 Huxley EJ, Viroslav J, Gray WR, et al. Pharyngeal aspiration in normal adults and patients with depressed consciousness. Am J Med 1978; 64: 564-568.

4 Gleeson K, Eggli DF, Maxwell SL. Quantitative aspiration during sleep in normal subjects. Chest 1997; 111: $1266-1272$.

5 Jones R, Pearson J, Ward C. Functional dyspepsia. N Engl J Med 2016; 374: 895.

6 Rowbotham NJ, Smith S, Leighton PA, et al. The top 10 research priorities in cystic fibrosis developed by a partnership between people with CF and healthcare providers. Thorax 2018; 73: 388-390.

7 Sweet MP, Patti MG, Hoopes C, et al. Gastro-oesophageal reflux and aspiration in patients with advanced lung disease. Thorax 2009; 64: 167-173.

8 McDonnell MJ, O'Toole D, Ward C, et al. A qualitative synthesis of gastro-oesophageal reflux in bronchiectasis: Current understanding and future risk. Respir Med 2018; 141: 132-143.

9 McDonnell MJ, Aliberti S, Goeminne PC, et al. Comorbidities and the risk of mortality in patients with bronchiectasis: an international multicentre cohort study. Lancet Respir Med 2016; 4: 969-979.

Copyright @ERS 2018 